\title{
Centenário Paulo Freire: Contribuições do Ideário Freireano para a Educação em Ciência
}

\author{
Demétrio Delizoicov, ${ }^{(1)}$ Simoni Tormöhlen Gehlen, ${ }^{(1)}$ Stefannie de Sá Ibraim
}

A concepção educacional de Paulo Freire emerge nos anos 1960 quando, desafiado pelo problema do alto índice de analfabetismo brasileiro, inicia uma práxis cuja primeira síntese é apresentada no seu livro Educação como prática de liberdade. Perseguido e detido em prisão por cerca de dois meses pela ditadura militar implantada no Brasil em 1964, Freire se exilou no Chile, onde permaneceu até 1969.

Durante o período em que viveu no Chile se engajou em uma equipe de especialistas de várias áreas do conhecimento, na qual destacavam-se os agrônomos. Esta equipe tinha como foco a reforma agrária que estava sendo iniciada pelo governo eleito em 1964. Dentre outros problemas oriundos dessa iniciativa, a educação dos agricultores para a implementação da pretendida reforma, possibilitou que Freire, junto a tal equipe, realizasse uma nova síntese de suas concepções educacionais, fomentada pelo trabalho realizado, a qual foi publicada nos livros Pedagogia do Oprimido e Extensão ou Comunicação? Nos livros há um olhar crítico para as práxis educativas que se originaram no processo que estava sendo estabelecido. Assim, Freire amplia suas reflexões gnosiológicas e educacionais para além de uma educação destinada a analfabetos, ainda que tenha mantido como foco prioritário a educação não escolar. Ele considera que, além da leitura, o processo educativo em construção, deveria propiciar o estabelecimento de práticas agrícolas inéditas para os camponeses, que já eram estabelecidas e implementadas em outros espaços. Assim, o autor aprofunda tanto a sua compreensão gnosiológica como a educacional. 
Em relação à concepção gnosiológica, Freire assume três pressupostos fundamentais: (i) o sujeito do conhecimento é inconcluso e se constitui na sua relação tanto com seres humanos, como nas suas relações com a natureza bruta e a transformada por seres humanos; (ii) o conhecimento é incompleto, em sintonia, por exemplo, com o processo histórico relativo à produção das teorias científicas quando se consideram as superações de algumas delas, ou seja, o conhecimento é devir; e (iii) os problemas que fazem avançar o processo histórico da humanização do Homo sapiens são os que permitem que o ser humano se torne um ser mais, ou seja, é porvir. Portanto, o autor prioriza e problematiza a compreensão de situações que provocam a desumanização, sendo elas as que orientam privilegiadamente processos educativos.

São esses três fundamentos gnosiológicos que estabelecem distinções entre posicionamentos críticos sobre a possibilidade de conhecer, e os posicionamentos relativísticos sobre a possibilidade do conhecimento, com seus impactos em distintas concepções educacionais. Há perspectivas educacionais que adotam uma concepção epistemológica crítica, mas, no entanto, mitigam, ou mesmo desconsideram, o terceiro fundamento da concepção gnosiológica freireana. Esse fundamento estabelece critérios para que não se deixe de ser abordado em processos educativos os conhecimentos que têm desumanizado seres humanos ao longo da história, levando em conta tanto a dimensão temporal como a espacial. Daí os adjetivos nos dois livros como prática de liberdade e dos oprimidos. Freire explicita, nos títulos, que a educação imprime direcionamentos já que não é neutra, sobretudo por envolver por quê e para quem os educadores planejam, conscientemente ou não, suas práticas educativas.

Em sintonia com essas premissas gnosiológicas, Freire aprofunda na sua obra as relações estabelecidas com os fundamentos de suas concepções educacionais. Deste modo, ele analisa o papel das(os): (i) dialogicidade, porque o ser humano, como porvir se constitui na sua relação com outros; (ii) problematização, porque o conhecimento é devir, ele surge como um desafio no enfrentamento de problemas; (iii) conscientização, porque a educação não é neutra; $e$ (iv) procedimentos de seleção tanto dos problemas que desumanizam, como dos conhecimentos históricos que contribuem para a superação da desumanização. Essa seleção resulta em temas, que Freire adjetiva de geradores, e são identificados por meio de uma busca cujos procedimentos são explicitados por Freire no processo por ele denominado de investigação temática.

Assim compreendidas as concepções gnosiológicas e educacionais de Freire, o ideário freireano passa a ser foco de grupos de pesquisa em Educação em Ciências (EC) desde a década de 1970, quando surgem os Programas de Pós-graduação e congressos específicos dessa área. Os desafios priorizados e enfrentados por esses grupos de pesquisa em EC, inicialmente com foco no ensino fundamental, foram: (i) implementar práticas em sintonia com o ideário freireano no âmbito da educação escolar na EC; (ii) articular abordagem temática e conceitos científicos; (iii) implementar a dialogicidade e a problematização como práticas docente; e (iv) incluir o ideário e práticas freireanas na formação de professores. 
Resultados iniciais dessas pesquisas foram publicados no artigo de Delizoicov (1983) fundamentado nas dissertações de Angotti (1982) e de Delizoicov (1982), defendidas no Curso de Mestrado em Ensino de Ciências (modalidade Física) da USP. Ao longo dos anos, pesquisas com foco nas concepções de Freire foram intensificadas por outros pesquisadores e grupos de pesquisa. Alguns resultados delas foram obtidos a partir da implementação, durante 1989-1992, da concepção freireana na rede municipal de educação do município de São Paulo (Secretaria Municipal de Educação de São Paulo - SME-SP, 1992; Pernambuco, 1993).

Além disso, nas quatro últimas décadas encontram-se iniciativas de pesquisa em EC fundamentadas no ideário freireano que, mesmo não articuladas especificamente com propostas curriculares organizadas por secretarias de educação, implementam alguns pressupostos de Freire na disciplina de Ciências do Ensino Fundamental e nas de Biologia, Física e Química do Ensino Médio.

No presente dossiê, comemorando os 100 anos de Paulo Freire, são apresentados quatorze artigos, produzidos por pesquisadores de diferentes regiões do Brasil e da América Latina, os quais estão divididos em cinco grupos, a saber: teórico, revisão bibliográfica, contexto de formação básica, contexto de formação inicial e contexto não-escolar. Assim, ele simboliza uma pequena parcela das publicações relacionadas às obras de Paulo Freire, no contexto da Educação em Ciências, mas é representativo da amplitude do diálogo que pode ser estabelecido com às perspectivas educacionais.

O primeiro grupo envolve três artigos que têm como foco o aprofundamento teórico-metodológico de alguns aspectos da perspectiva freireana e possíveis relações com a Educação Ciência-Tecnologia-Sociedade (CTS). Considerando a educação escolar, o primeiro artigo do dossiê, intitulado: "Alteridade, Pesquisa na Educação em Ciências e a Perspectiva Freireana”, de autoria de Demétrio Delizoicov e Antônio Fernando Gouvêa da Silva, aborda as especificidades da contextualização da concepção de educação de Paulo Freire e a contribuição de Enrique Dussel para a dimensão axiológica do currículo. E, no contexto dessas discussões, os autores apresentam argumentos que fundamentam a alteridade na implementação da concepção freireana na educação escolar. Em "Freire, Fermento entre os Oprimidos: Continua Sendo?”, o autor Décio Auler problematiza algumas questões da obra de Paulo Freire e sinaliza que há uma incompletude e fragilidade quanto a aspectos que envolvem a concepção de sujeitos históricos. Para superar essa incompletude, o autor aponta aproximações entre Freire e o Pensamento Latino-Americano em Ciência-Tecnologia-Sociedade (PLACTS) e a necessidade de se ampliar a categoria diálogo. E, seguindo esse contexto das aproximações entre Freire e PLACTS, Suiane Ewerling da Rosa e Roseline Beatriz Strieder, no artigo intitulado "Perspectivas para a Constituição de uma Cultura de Participação em Temas Sociais de Ciência-Tecnologia", definem e caracterizam elementos que contribuem para situar e constituir mecanismos ampliados de participação em temas sociais que envolvem ciência-tecnologia, sinalizando caminhos para a constituição de processos democráticos ampliados no contexto da educação CTS. 
O segundo grupo é composto por dois artigos de revisão bibliográfica, com foco em pesquisas brasileiras. No artigo "Como Ocorre a Construção e Disseminação do Conhecimento Curricular Freireano? Algumas Sinalizações", Thiago Flores Magoga e Cristiane Muenchen investigam elementos e contextos importantes, que auxiliam na construção e disseminação do conhecimento curricular freireano, tendo como referência a materialização da perspectiva de Temas Geradores. E no trabalho "Releituras de Paulo Freire na Educação em Ciências: Pressupostos da Articulação Freire-CTS”, Eliane dos Santos Almeida e Roseline Beatriz Strieder buscam identificar propósitos e pressupostos da articulação entre a Educação CTS e a perspectiva freireana, para compreender por que e para que essa articulação tem sido tecida. De modo geral, os artigos deste grupo sinalizam que há um significativo avanço na pesquisa em Educação em Ciências, quanto a releituras e à materialização de alguns aspectos da obra de Paulo Freire.

$\mathrm{O}$ terceiro grupo contempla quatro artigos, os quais mobilizam diferentes aspectos da obra de Paulo Freire para problematizar e buscar uma formação mais crítica, libertadora e contextualizada. Em "A relação Teoria-Prática Docente no Ensino de Ciências: Uma Análise Materialista Histórico-Dialética à Luz da Práxis Autêntica de Freire", Cristiane Aparecida Madureira e Juliana Rezende Torres discutem a relação teoria-prática docente frente à práxis autêntica freireana. As autoras sinalizam que o movimento dialético estruturante da práxis somado à consciência do trabalho docente influencia a dimensão da práxis pedagógica do docente. Enfatizando a transformação das realidades a partir da formação dos estudantes, Fabrício Masaharu Oiwa da Costa, Carla Sarmento Santos e Giselle Watanabe, em "Alguns Parâmetros da Criticidade e da Complexidade em Propostas de Aulas Socioambientais Presenciais e Remotas", analisam a experiência da produção de duas propostas de aula nos contextos remoto e presencial e argumentam a favor de uma formação crítica e complexa. Gabriel Ribeiro Demartini e Antônio Fernando Gouvêa da Silva, em "Abordagem Temática Freireana no Ensino de Ciências e Biologia: Reflexões a partir da Práxis Autêntica", investigam em que medida a educação libertadora pode fundamentar práticas curriculares transformadoras de uma realidade sociocultural injusta. Por fim, Alejandra E. Defago e Raúl Esteban Ithuralde, em "Leyendo una Currícula de Ciencias Naturales en un Abordaje Freiriano: El Caso de los Diseños Curriculares de la Provincia de Buenos Aires, Argentina", ao discutirem aspectos presentes em Projetos Curriculares da província de Buenos Aires, destacam práticas que se aproximam progressivamente da Educação Popular. Em linhas gerais, esses trabalhos sinalizam a importância de considerar a compreensão dos educandos sobre suas realidades no contexto de práticas educativas, construindo vínculos com as comunidades, e contribuindo para a autonomia dos sujeitos.

O quarto grupo representa reflexões sobre a formação inicial de professores visando contribuir para um ensino problematizador da realidade e é composto por quatro artigos. Eril Medeiros da Fonseca, Tassiéllen Soares Antunes Tadeu, André de Azambuja Maraschin e Renata Hernandez Lindemann, no texto "Problematização das Situações-Limite no Contexto do Ensino e Formação em Ciências: Contribuições da 
Abordagem de Temas com Viés Freireano", identificam e problematizam situações-limite na formação de professores de Ciências, sinalizando possibilidades de enfrentamento da prática pedagógica. Ana Paulo Solino, Polliane Santos de Sousa, Roger Magalhães da Silva e Simoni Gehlen, em "O Tema Gerador na Formação de Pedagogas do alto Sertão Alagoano: Da Escuta Sensível ao Planejamento de Ciências", discutem os desafios e potencialidades na elaboração de planejamentos didáticos-pedagógicos para a Educação em Ciência à luz da Abordagem Temática Freireana. Fábio Peres Gonçalves, Renata Aragão da Silveira e Lya Piaia, em "A Problematização do Formador de Professores de Química no Estudo da Abordagem Temática: Uma Análise Constituinte de um Processo de Comunicação", investigam a problematização promovida por um formador em uma proposta baseada na Abordagem Temática no contexto de estágio curricular de Química. No contexto de educação do campo, Danilo Seithi Kato, Daniela Corsino Sandron Colombo e Marilisa Hoffmann, em "Diálogos Interculturais entre Conhecimentos Tradicionais e Conhecimentos Científicos em uma Comunidade Geraizeira: Um Olhar Freiriano na Licenciatura em Educação do Campo", analisam as potencialidades de diálogos interculturais no Ensino de Ciências, a partir da vivência de uma licencianda. Em síntese, os trabalhos deste grupo buscam romper com uma prática docente descontextualizada e aproblemática, destacando as contribuições da Abordagem Temática Freireana, das situações-limite e dos Temas Geradores. Ainda, eles contribuem para reflexões sobre o papel docente na educação libertadora e a dinâmica da Pedagogia da Alternância.

Encerrando o dossiê temático, o quinto grupo envolve reflexões sobre a obra de Paulo Freire em contexto não-escolar. No artigo "Diseños Globales e Historias Locales: Origen y Desarrollo de una Propuesta Educativa en un Museo Interactivo de Ciencias y Tecnologías en el Sur", Manuel Franco-Avellaneda e Diego Corrales-Caro, fundamentados no referencial freireano e nos estudos sociais da ciência e tecnologia, os autores apresentam as condições de produção, desenvolvimento e consolidação de uma proposta educativa no contexto de um museu interativo de Ciência e Tecnologia em Bogotá, na Colômbia. 


\title{
Referências
}

Angotti, J. A. P. S. (1982). Solução alternativa para a formação de professores de Ciências. (Dissertação de mestrado. IFUSP/FEUSP). São Paulo.

Delizoicov, D. (1983). O ensino de física e a concepção freireana da educação. Revista de Ensino de Física. 5(2), 85-98.

Delizoicov, D. (1982). Concepção problematizadora do ensino de ciências na educação formal. (Dissertação de mestrado. IFUSP/FEUSP). São Paulo.

Pernambuco, M. M. C. (1993).Significações e realidade: conhecimento. In N. Pontuschka, (org.). Ousadia no diálogo - Interdisciplinaridade na escola pública. Edições Loyola.

Secretaria Municipal de Educação de São Paulo - SME-SP (1992). Ciências: Visão da Área. Movimento de Reorientação Curricular. DOT/SME-SP.

\author{
Demétrio Delizoicov \\ Universidade Federal de Santa Catarina \\ demetrio.neto@ufsc.br \\ ${ }^{\circledR}$ Simoni Tormöhlen Gehlen \\ Universidade Estadual de Santa Cruz \\ stgehlen@uesc.br \\ Stefannie de Sá Ibraim \\ Universidade Federal de Minas Gerais \\ stefannieibraim@ufmg.br
}

